\title{
The global prevalence of osteoporosis in the world: a comprehensive systematic review and meta-analysis
}

\author{
Nader Salari ${ }^{1}$, Hooman Ghasemi ${ }^{2}$, Loghman Mohammadi ${ }^{3}$, Mohammad hasan Behzadi ${ }^{3}$, Elham Rabieenia ${ }^{2}$,
} Shamarina Shohaimi ${ }^{4}$ and Masoud Mohammadi ${ }^{*}$ (1)

\begin{abstract}
Background: Osteoporosis affects all sections of society, including families with people affected by osteoporosis, government agencies and medical institutes in various fields. For example, it involves the patient and his/her family members, and government agencies in terms of the cost of treatment and medical care. Providing a comprehensive picture of the prevalence of osteoporosis globally is important for health policymakers to make appropriate decisions. Therefore, this study was conducted to investigate the prevalence of osteoporosis worldwide.

Methods: A systematic review and meta-analysis were conducted in accordance with the PRISMA criteria. The PubMed, Science Direct, Web of Science, Scopus, Magiran, and Google Scholar databases were searched with no lower time limit up till 26 August 2020. The heterogeneity of the studies was measured using the $P^{2}$ test, and the publication bias was assessed by the Begg and Mazumdar's test at the significance level of 0.1 .

Results: After following the systematic review processes, 86 studies were selected for meta-analysis. The sample size of the study was 103,334,579 people in the age range of 15-105 years. Using meta-analysis, the prevalence of osteoporosis in the world was reported to be 18.3 (95\% Cl 16.2-20.7). Based on 70 studies and sample size of 800,457 women, and heterogenicity $P^{2}: 99.8$, the prevalence of osteoporosis in women of the world was reported to be 23.1 (95\% Cl 19.8-26.9), while the prevalence of osteoporosis among men of the world was found to be 11.7 (95\% Cl 9.614.1 which was based on 40 studies and sample size of 453,964 men.). The highest prevalence of osteoporosis was reported in Africa with 39.5\% (95\% Cl 22.3-59.7) and a sample size of 2989 people with the age range 18-95 years.

Conclusion: According to the medical, economic, and social burden of osteoporosis, providing a robust and comprehensive estimate of the prevalence of osteoporosis in the world can facilitate decisions in health system planning and policymaking, including an overview of the current and outlook for the future; provide the necessary facilities for the treatment of people with osteoporosis; reduce the severe risks that lead to death by preventing fractures; and, finally, monitor the overall state of osteoporosis in the world. This study is the first to report a structured review and meta-analysis of the prevalence of osteoporosis worldwide.
\end{abstract}

Keywords: Prevalence, Osteoporosis, Meta-analysis, Systematic review

*Correspondence: Masoud.mohammadi1989@yahoo.com

${ }^{5}$ Department of Nursing, School of Nursing and Midwifery, Kermanshah University of Medical Sciences, Kermanshah, Iran

Full list of author information is available at the end of the article

\section{Background}

Osteoporosis is a common disease all over the world. Osteoporosis has been operationally defined based on bone mineral density (BMD) assessment. According to the WHO criteria, osteoporosis is defined as a original author(s) and the source, provide a link to the Creative Commons licence, and indicate if changes were made. The images or other third party material in this article are included in the article's Creative Commons licence, unless indicated otherwise in a credit line to the material. If material is not included in the article's Creative Commons licence and your intended use is not permitted by statutory regulation or exceeds the permitted use, you will need to obtain permission directly from the copyright holder. To view a copy of this licence, visit http://creativecommons.org/licenses/by/4.0/. The Creative Commons Public Domain Dedication waiver (http://creativeco mmons.org/publicdomain/zero/1.0/) applies to the data made available in this article, unless otherwise stated in a credit line to the data. 
BMD that lies 2.5 standard deviations or more below the average value for young, healthy women (a $T$-score of $<-2.5 \mathrm{SD})(1,6)$. The most widely validated technique to measure BMD is dual-energy $\mathrm{X}$-ray absorptiometry (DXA), and diagnostic criteria based on the $T$-score for BMD area recommended entry criterion for developing pharmaceutical interventions in osteoporosis (7-9) [1].

Osteoporosis is classified as primary (includes type I and type II) and secondary. Primary osteoporosis is seen in post-menopausal women and men and women over 70 years of age due to ageing [2]. Secondary osteoporosis is caused by diseases, treatments or idiopathic. Systemic diseases, endocrine diseases, and malignant neoplasms are among the diseases that cause secondary osteoporosis. Besides, chronic use of glucocorticoids, lifestyle conditions, habits, and major depression are other causes of osteoporosis [2].

Various methods are used to measure osteoporosis. Typically, to diagnose osteoporosis, bone mineral density (BMD) is measured by dual-energy X-ray absorptiometry (DXA) at various skeletal sites [3]. Another way to diagnose osteoporosis is the speed of sound (SOS) in the tibia, which can be measured by ultrasound imaging [4].

Risk factors for osteoporosis are divided into two categories: modifiable and non-modifiable [5]. Weight, smoking, alcohol consumption [6], physical inactivity, dietary calcium deficiency, and long-term glucocorticoid use are among the risk factors for the modifiable osteoporosis group. Gender, age, race, and genetic characteristics are among the risk factors for the non-modifiable osteoporosis group [5]. These factors can also be more widespread with respect to gender. For example, in women, premature menopause and loss of ovarian function before menopause are other risk factors for osteoporosis [6].

A study in Turkey showed that women between the ages of 18-49 who smoke, have fair skin, or have a family history of osteoporosis are at higher risk for osteoporosis [7]. The clinical symptoms of osteoporosis in old age include decreased body height, dowager's hump or kyphosis, bone fracture and respiratory impairment [8].

In a double-blind placebo-controlled study in osteoporosis comprised of 483 women with post-menopausal osteoporosis, 110 women with secondary osteoporosis, and 84 men with osteoporosis of any cause, aged between 28 and 88 years old, the mortality rate in people with one or more fractures was 4.4 times higher [9]. The incidence of osteoporotic fractures has made it one of the leading causes of death in the elderly [3]. Because the risk of osteoporotic fractures is higher in older women than in older men, all menopausal women should be screened for signs of osteoporosis [10]. Fractures usually occur in three areas: vertebrae, distal arm, and hip [11].
Vertebral fractures are more common in women than men [11]. Research has shown that if women have to be divided into three groups; premenopausal (before menopause), the onset of menopause, and women with over five years of menopause, bone fractures due to osteoporosis were more common in post-menopausal women than in premenopausal women or around the onset of menopause [12]. Twenty per cent of women die within a year of a fracture [11].

Men have more bone mass during growth and develop more muscle mass, which provides more skeletal integration. Men do not experience menopause. Also, they have a shorter life expectancy than women; therefore, less time is available to develop the disease. The prevalence of osteoporosis in older men than in young men is also based on this fact [11].

Osteoporosis is a problem for both sexes. However, the majority of research on osteoporosis has focused on women because women are more likely than men to develop osteoporosis and subsequent fractures [11]. So far, many studies have been conducted on the prevalence of osteoporosis in different parts of the world. These studies have either been based on small samples from the target population [13], or to a lesser extent, based on all data collected in the medical databases of a country such as the USA [14] and Korea [15]. According to a study based on the SOS criteria in 2003, the prevalence of osteoporosis in Chinese women was reported to be $10.08 \%$ [4]. In another study in 2005, the prevalence of osteoporosis in Vietnamese women, based on the BMD criteria, was reported to be $15.4 \%$ [16].

Orthopaedic surgeons are typically only involved in the osteoporotic patient's care as a consequence of a fracture and with the single biggest risk factor for a future fracture being a previous fragility fracture, it, therefore, follows that the area of focus for the orthopaedist should be on the secondary prevention of future fractures $[9,10]$. With the instigation of the Own the Bone program by the AOA, the idea of the orthopaedist being a key component in the care of a patient's bone health, beyond the acute fracture care, has gained a great deal of traction $[10,11]$.

Interestingly enough, one of the fractures that is the most common in the osteoporotic individual is also the most often missed: vertebral body fractures. They are most often missed due to a lack of inclusion in the differential diagnosis of patients with back pain and are thus overlooked [11-14]. A vertebral body fracture should be suspected in any patient at risk for osteoporosis with back pain or kyphosis [11-14].

Studies in many different countries have demonstrated that with increased communication between the orthopaedist, patient and patient's PCP, there is increased 
usage of pharmacotherapeutics, calcium and vitamin D supplementation, and BMD assessment with DXA scan [14-17]. There is also good evidence that the use of calcium, vitamin D and pharmaceutical interventions results in a decreased risk of fragility fractures [14-17].

A study of 773 Indian men and women between the ages of 30 and 90 showed that the prevalence of osteoporosis was $24.7 \%$. The prevalence in women was reported to be $15 \% ; 10.3 \%$ was related to post-menopausal women, and $4.7 \%$ to premenopausal women. In this study, the prevalence in men was reported to be $9.7 \%$ [17].

The prevalence of osteoporosis in a sample of 524 Indian people between the ages of 20 and 85 was reported to be $6.9 \%, 11.1 \%$ of which were women, and $3.9 \%$ were men [18].

According to the data taken in a random sample from the Taiwan National Health Insurance (NHI) database in 2006, the prevalence of osteoporosis in Taiwanese men over the age of 50, based on BMD criteria, was reported to be $1.63 \%$ [19]. While in a survey in 2018 , this rate was reported at 9.7\% [19-21].

In another study, the prevalence of osteoporosis in Saudi Arabia men between the ages of 30 and 90 years was reported to be $24.1 \% ; 19.2 \%$ of which was related to the age range of $30-50$ years and $23.5 \%$ was related to the age range of $50-90$ years [21].

These discrepancies in reports of the prevalence of osteoporosis can be seen in research in other parts of the world.

It is important to have consistent information on the prevalence of osteoporosis worldwide. With increasing life expectancy and longevity, the prevalence of osteoporosis and related fractures is increasing [15]. This is a serious challenge not only for health officials but also for individuals and their families and society in general [15]. Determining the prevalence and incidence of osteoporotic fractures is the first step in adopting the necessary strategies to reduce the burden of this challenge and concerns [15]. Due to the dispersion of reports related to the prevalence of osteoporosis in the world, which was based on small and large samples, and also lack of estimates of the prevalence worldwide, we decided to have a systematic review of all studies conducted in this field and examined the worldwide prevalence of osteoporosis, using meta-analysis tools.

Therefore, this study aims to investigate the systematic analysis of evidence and studies to report the prevalence of osteoporosis worldwide.

\section{Methods}

\section{Search strategy and study selection procedure}

Searches in this meta-analysis study were performed by two researchers. As part of the research methodology,
PubMed, Science Direct, Web of Science, Scopus and Persian language databases such as SID and Magiran were searched with limited English and Persian language and no time limit until August 2020. The keywords used to search for resources were selected from the Medical Subject Headings (MeSH) database in this study. A search using keywords osteoporosis, osteoporosis, prevalence, cross-sectional, age-related, post-traumatic, and all the possible combinations of these words were designed according to the pattern of each database. All information related articles were identified and added to the EndNote bibliography management software. In addition to maximize the comprehensiveness of the search, the lists of references in the identified articles were manually reviewed. After collecting articles, the duplicate papers that were identified within various databases were excluded.

Search strategy in all databases: $((()((($ osteoporosis [Title/Abstract]) OR Age-Related Osteoporosis [Title/ Abstract]) OR Bone Loss [Title/Abstract]) OR Post-Traumatic [Title/Abstract]) OR Senile Osteoporosis [Title/ Abstract]) AND prevalence OR Period Prevalence OR Point Prevalence)))))))

Inclusion criteria were as follows: Studies that have examined the prevalence of osteoporosis, observational (cross-sectional) studies, and studies whose full text was available.

Exclusion criteria were as follows: Duplicate studies, unrelated studies to the subject and purpose of this study, unclear methodology, interventional studies, case report studies, studies whose full text was not available, and studies whose language was not Persian or English.

\section{Study selection procedure}

Initially, all articles related to osteoporosis were collected, and a list of abstracts was prepared after the search was completed. At this point, all articles titled 'Prevalence' and 'Osteoporosis' entered the initial list. Then, a checklist appropriate to the type of study was used, which includes author's name, title, year and month of publication, place of study, sample size, the overall prevalence, and risk factors for all studies that were initially evaluated were prepared for final evaluation. Accordingly, the full text of the remaining articles from the previous stage, i.e. screening, were carefully examined, and irrelevant studies were excluded by considering the inclusion and exclusion criteria. In order to prevent bias, all stages of resource review and data extraction were performed by two reviewers independently. If an article was not included, the reason for the exclusion was mentioned. Then, those articles that included patients with osteoporosis were finally approved. In the end, 86 relevant articles entered the meta-analysis stage. The full text of the articles was reviewed for final analysis. 


\section{Quality evaluation}

To evaluate the quality of articles (i.e. methodological validity and results), a checklist appropriate to the type of study was used. STROBE checklists are commonly used to critique and evaluate the quality of observational studies, such as the present study. The STROBE checklist consists of six scales/general sections: title, abstract, introduction, methods, results, and discussion. Some of these scales have subscales, resulting in a total of 32 subscales/items. Accordingly, the maximum score that could be obtained using the STROBE 32 checklist is 32 [20]. Considering the score of 16 as the cut-off point, articles with scores of 16 or above were considered medium- or high-quality articles. Furthermore, articles with scores below 16 were considered weak- or low-quality articles and excluded from the study. In the present study, based on the evaluation conducted using the STROBE checklist, 86 articles were entered for the systematic review and meta-analysis process.

\section{Statistical analysis}

Since the prevalence rate has a binomial distribution, the variance of the prevalence was calculated using the binomial distribution formula, and the average weight was used to combine the prevalence rate in different studies. As well as to evaluate the heterogeneity of the selected studies, the $I^{2}$ index was used. Therefore, the random effects model was used to combine the results of the studies. Meta-regression was used in order to investigate the relationship between the prevalence of osteoporosis and the year of study and sample size. To investigate the publication bias, due to the high volume of samples entered into the study, the Begg and Mazumdar's test and corresponding Funnel plots were adopted with a significance level of 0.1. Data analysis was performed using the Comprehensive Meta-Analysis (Version 2) software.

\section{Results}

As shown in Fig. 1 and based on the initial search in the database, 2280 articles were found, of which 491 articles were extracted from the PubMed database, 166 articles from the Science Direct database, 949 articles from Web of Science, 649 articles from Scopus, seven articles from SID, and 18 articles from Magiran. Out of the total number of articles, 717 articles were duplicates that were excluded in the first stage. In the screening stage, 1429 articles were excluded by considering the inclusion and exclusion criteria and the application of time limit from 2000 to 2020. Eight articles that seemed to be related to the study were excluded from the study due to the lack of access to their full text. In the eligibility evaluation stage, the full texts of the remaining
134 articles were examined based on the inclusion and exclusion criteria, and 48 irrelevant articles were omitted. The studies were reviewed based on the four-step process of PRISMA2009 (Fig. 1), including identifying articles, screening, reviewing the criteria for accepting articles, and the articles that entered the meta-analysis process. Finally, 86 articles were included in the final analysis; their information is given in Table 1.

Due to the heterogeneity of the selected studies, the $I^{2}$ test $\left(I^{2}=97.9\right)$ and the random effects model were used to combine the reported results of studies and approximate the total prevalence. However, according to the results of Begg and Mazumdar's test and funnel diagram at a significance level of 0.1 , no bias was observed in the results of the prevalence of osteoporosis worldwide in this study $(P=0.103)$ (Fig. 2).

\section{Meta-analysis}

A total of 86 studies were used to assess the prevalence of osteoporosis in the world, including 64 studies examining the prevalence of osteoporosis in Asian countries, nine studies in the European population, nine studies in the USA, three studies in Africa, and one study in Australia. The sample size was $103,334,579$ people in the age range 15-105 years, and the prevalence of osteoporosis in the world was reported to be 18.3 (95\% CI 16.2-20.7). The midpoint of each line segment indicates the prevalence in each study, and the diamond shape indicates the prevalence in the population for the entire study (Fig. 3).

In addition to reporting the prevalence of osteoporosis worldwide, the prevalence of this disease across five continents was also reported in this study. Table 2 shows the prevalence of osteoporosis in the world and by continent. Accordingly, the highest prevalence of osteoporosis was reported in Africa with 39.5\% (95\% CI 22.3-59.7). Based on the results of Begg and Mazumdar's test at a significance level of 0.1, no bias was observed in the results prevalence of osteoporosis in the world and by continents $(P>0.05)$. However, the number of reported epidemiological studies on osteoporosis in Africa is limited. Based on the results of this study, it was revealed that the prevalence of osteoporosis in Africa is much worse than in other continents. The prevalence of osteoporosis in the Americas is far better than that in Europe and Asia. The prevalence of osteoporosis in Asia is higher than that in the USA and Australia. Likewise, the prevalence of osteoporosis in Asia is lower than in Africa and Europe.

The results of prevalence of osteoporosis in terms of diagnostic tools are reported in Table 2, according to which the highest prevalence of osteoporosis with BMD instrument was 19.6 (95\% CI 14.3-26.2). 


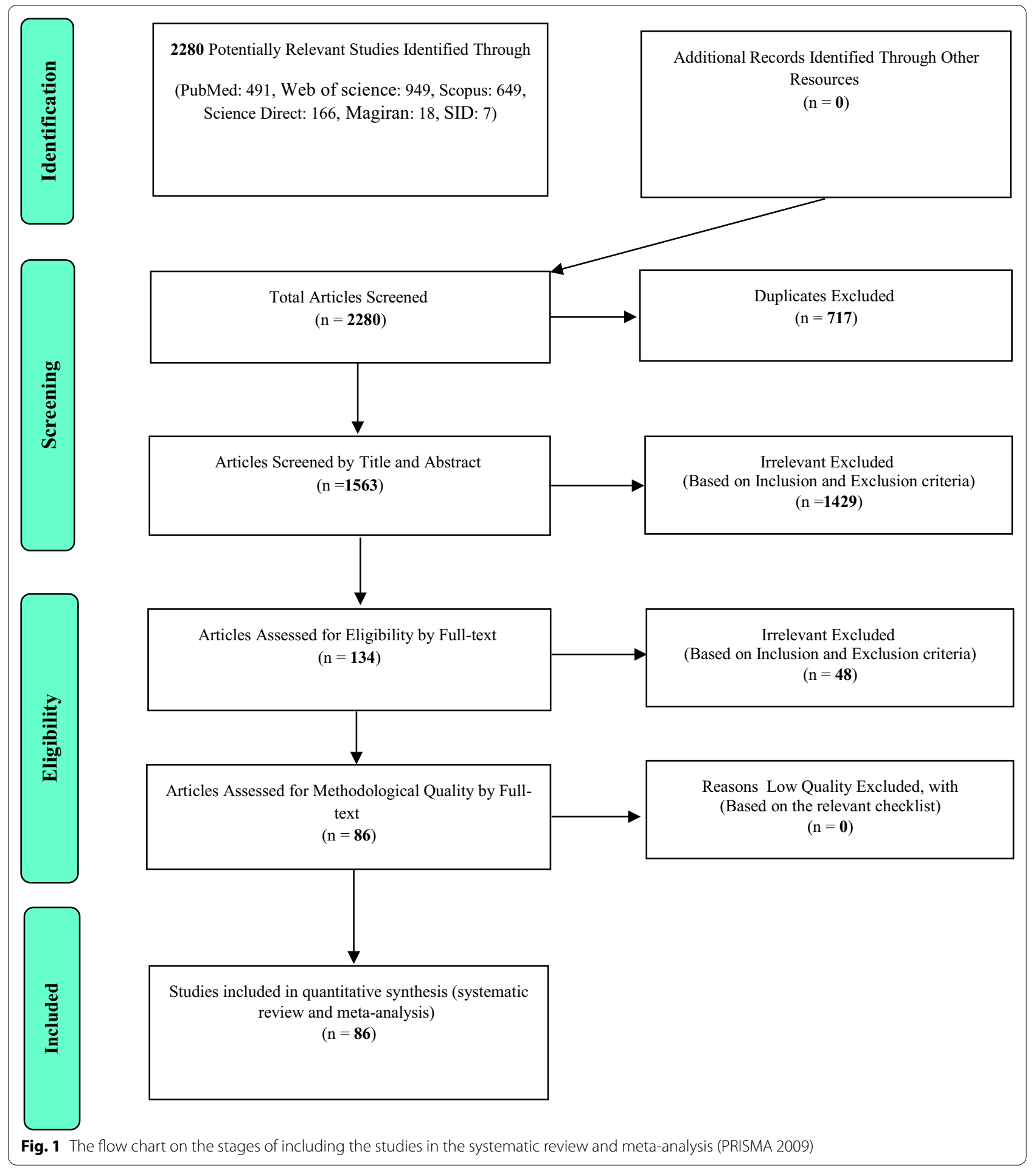

\section{Prevalence of osteoporosis in women}

In Fig. 4, based on 70 studies and sample size of 800,457 women and heterogenicity $\left(I^{2}: 99.8\right)$, the prevalence of osteoporosis in women of the world was reported to be 23.1 (95\% CI: 19.8-26.9). According to the results of Begg and Mazumdar's test at a significance level of 0.1 , no bias was observed in the prevalence of osteoporosis in women of worldwide in this study $(P=0.227)$. The analysis of the results of the prevalence of osteoporosis by sex on each continent is reported in Table 3. 


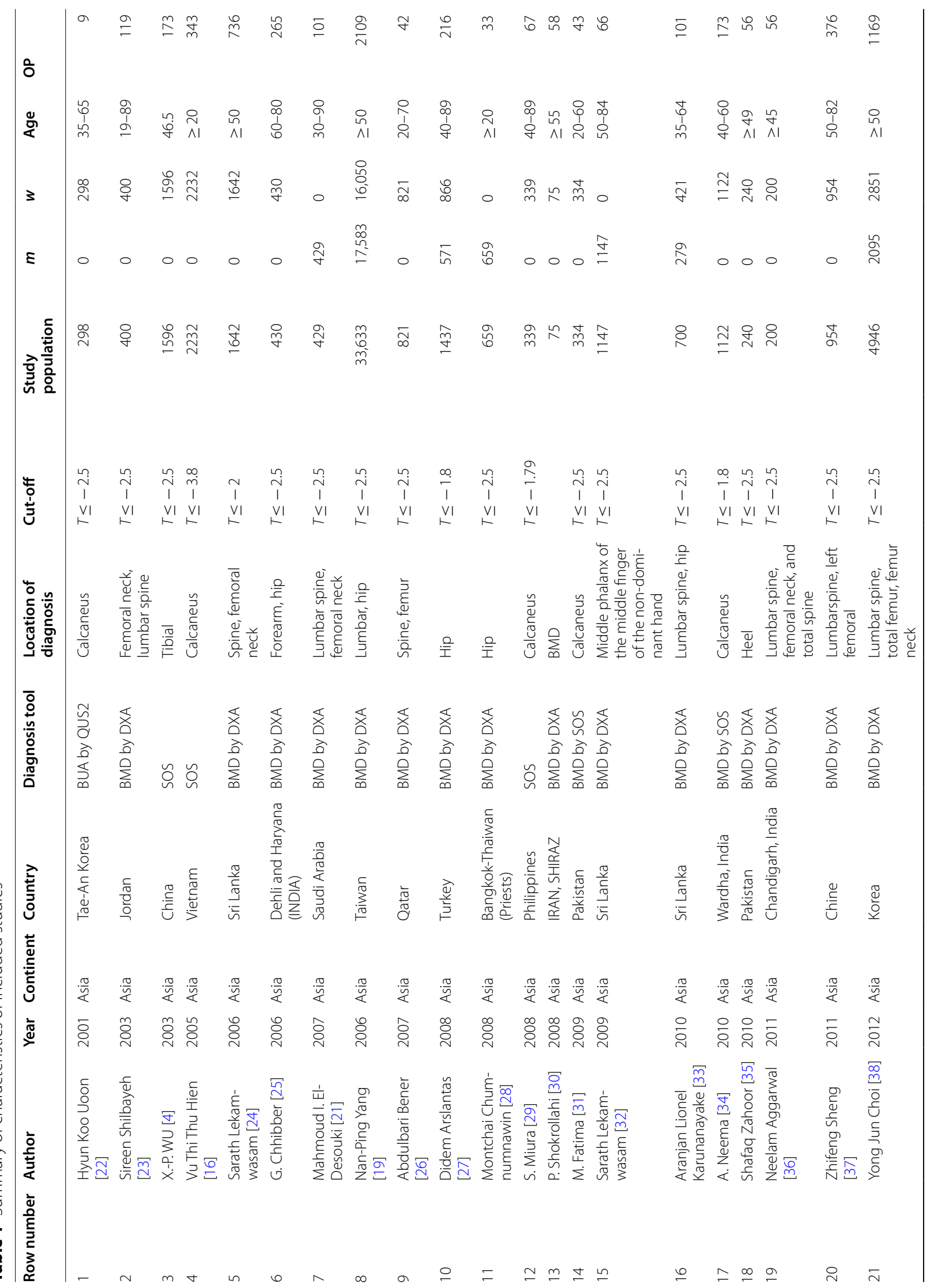




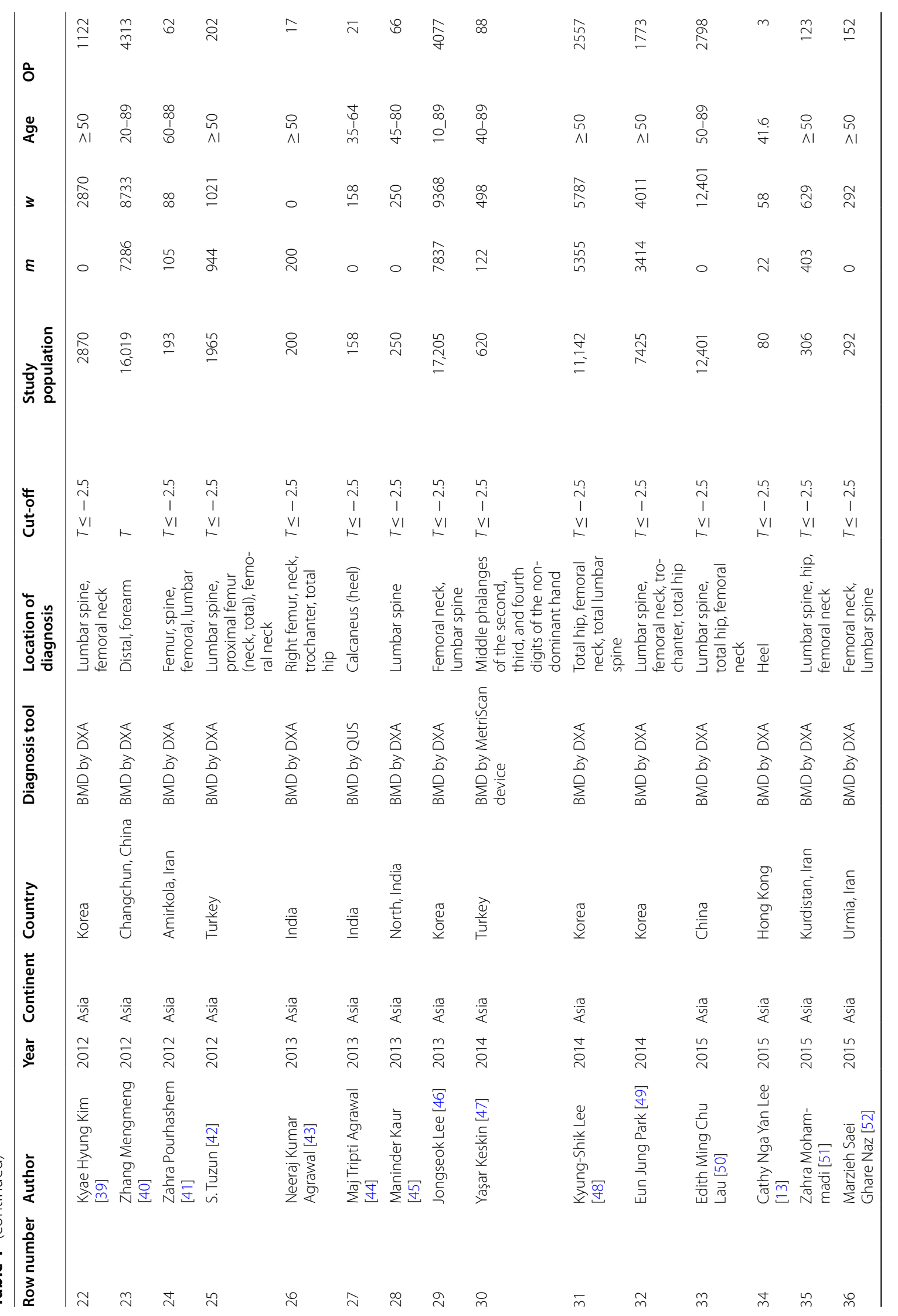




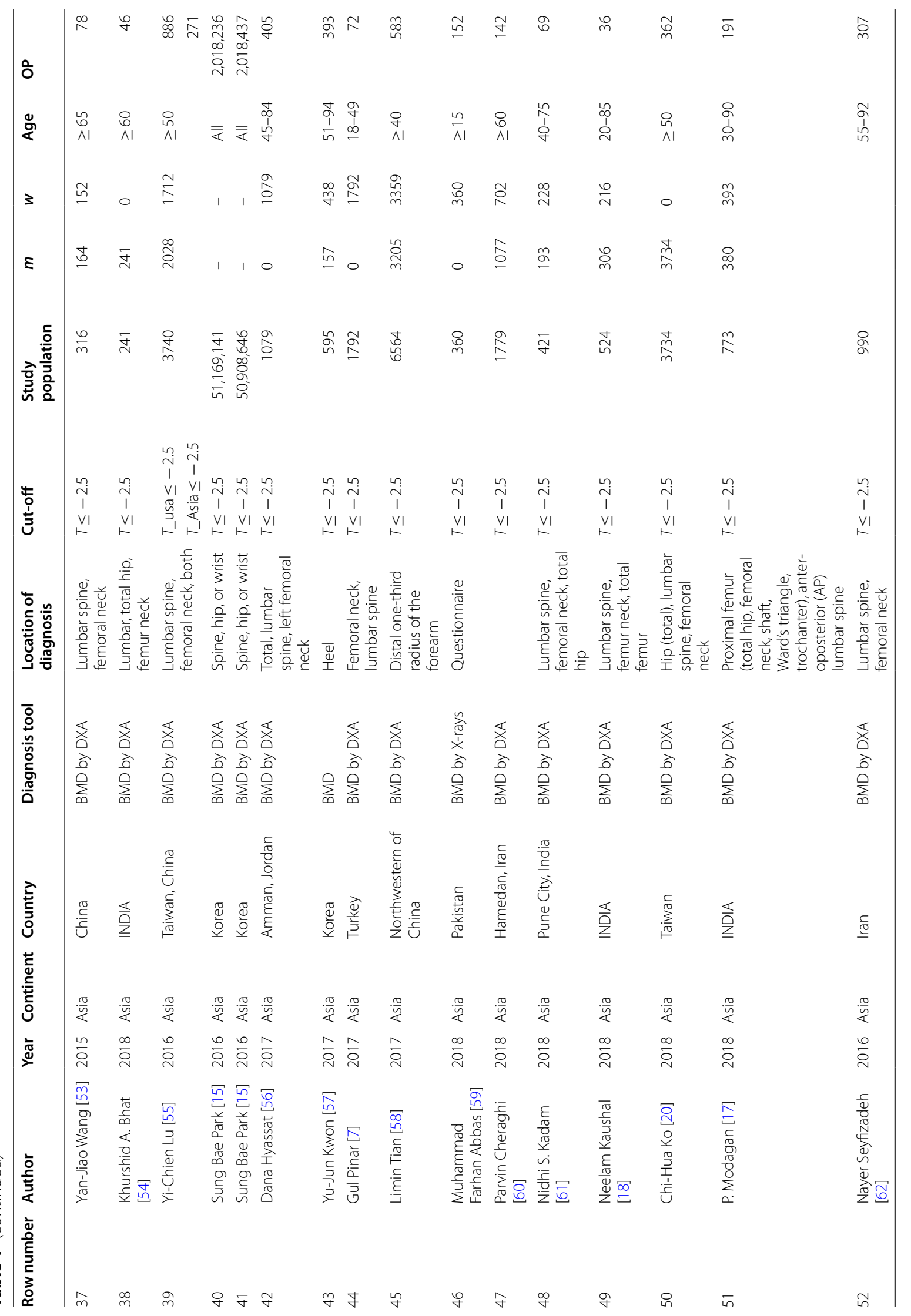




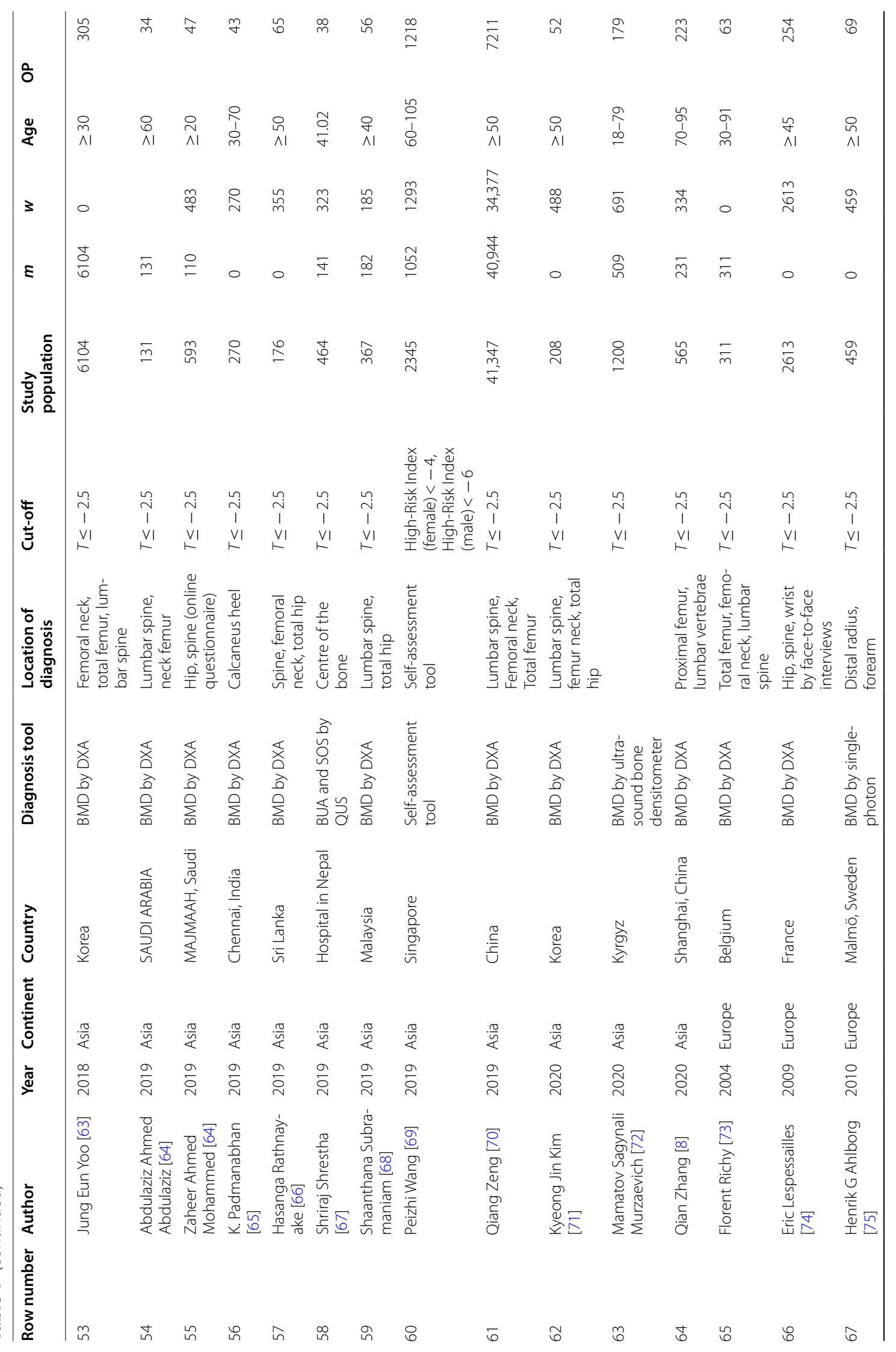




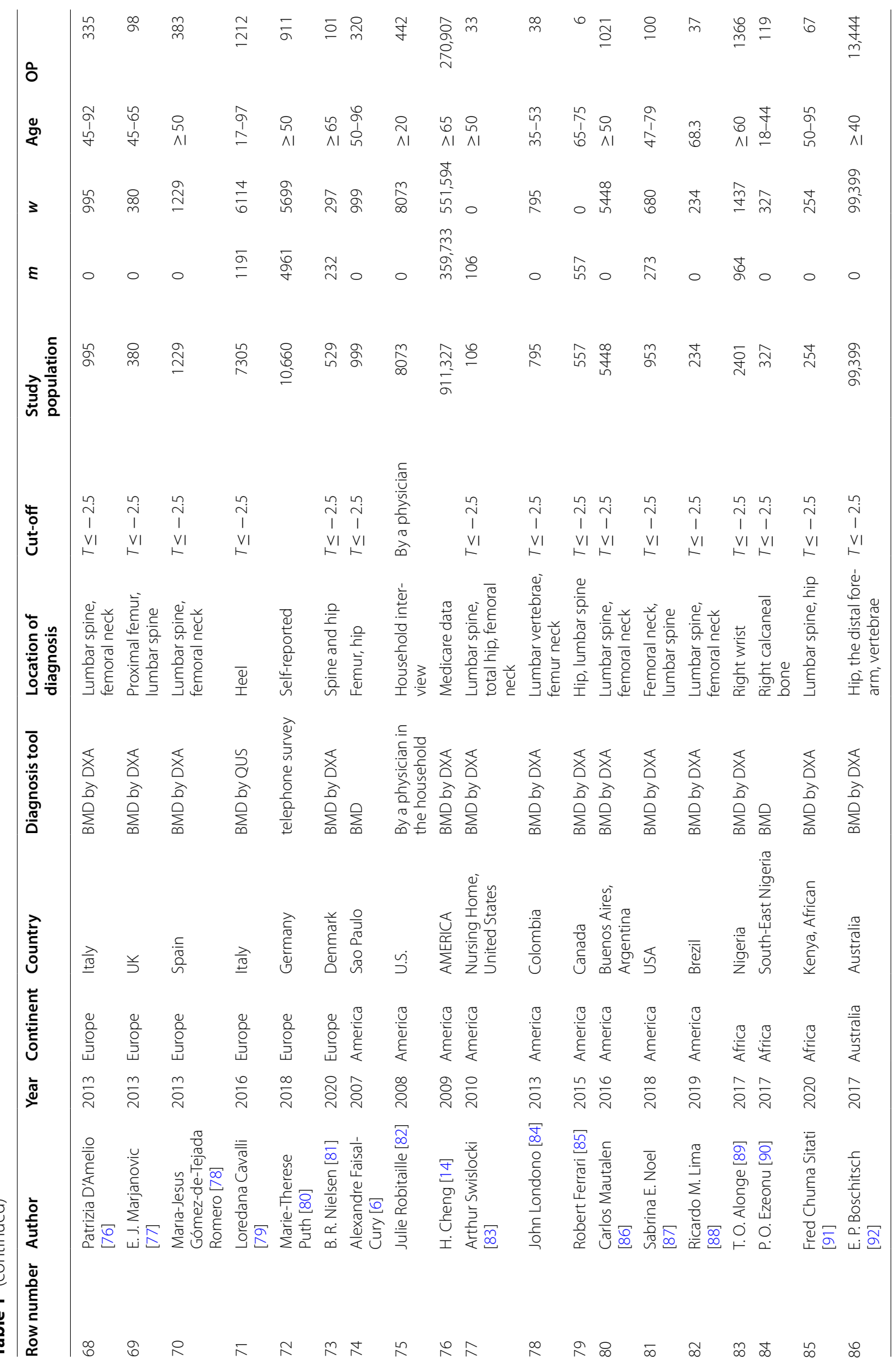




\section{Funnel Plot of Standard Error by Logit event rate}

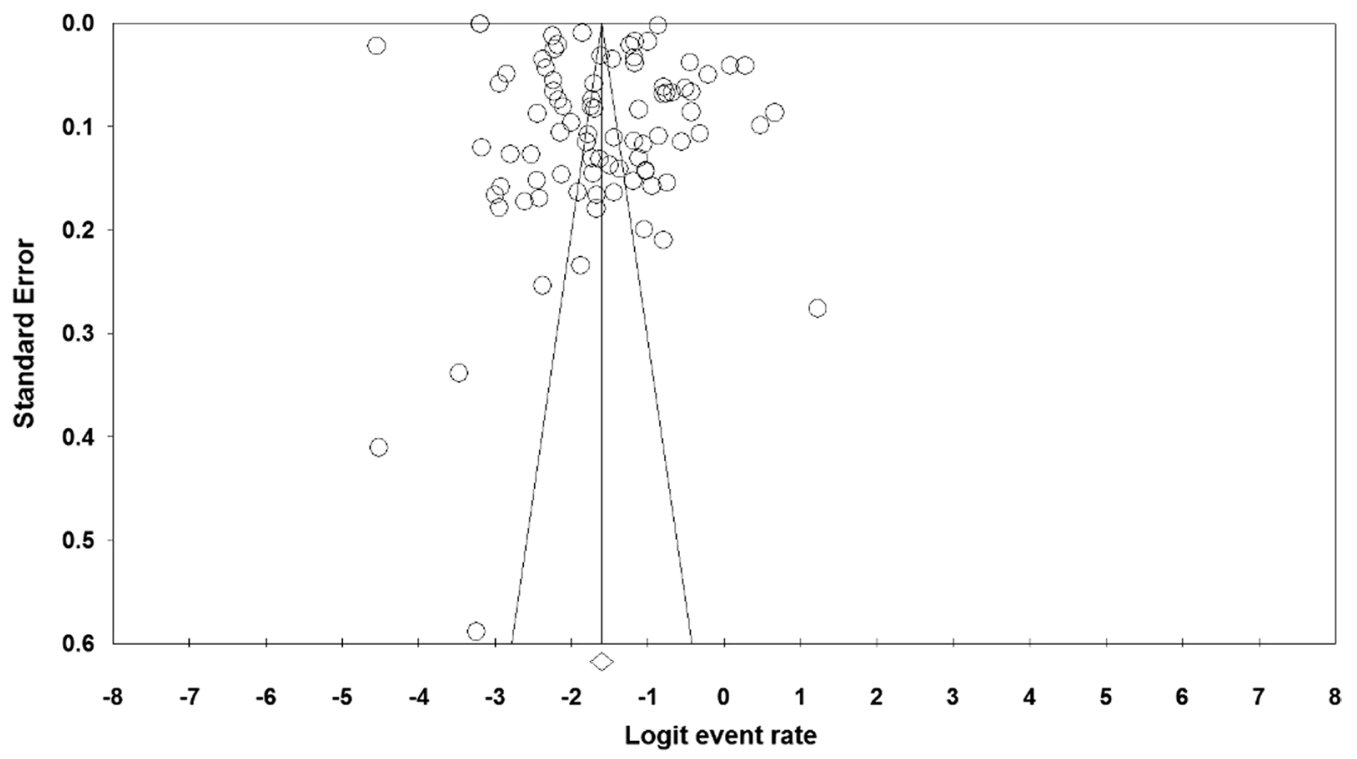

Fig. 2 Funnel diagram of the result of the overall prevalence of osteoporosis worldwide

\section{Prevalence of osteoporosis in men}

In Fig. 5, based on 40 studies and sample size were 453,964 men and heterogenicity $\left(I^{2}: 99.3\right)$, the prevalence of osteoporosis in men of the world was reported to be 11.7 (95\% CI 9.6-14.1). According to the results of Begg and Mazumdar's test at a significance level of 0.1 , no bias was observed in the results of the prevalence of osteoporosis in men worldwide in this study $(P=0.448)$. The analysis of the prevalence of osteoporosis by sex on each continent is reported in Table 3.

\section{Meta-regression test}

Given that the overall prevalence based on meta-analysis is influenced by factors such as sample size, year of research, age of study participants, place of study and gender, these factors increase heterogeneity and decrease the accuracy of results. Therefore, meta-regression analysis, as well as subgroup analysis, were used to examine the relationship between osteoporosis and this factors. Due to the effect of various factors in the incidence of heterogeneity between the results of osteoporosis studies globally, a meta-regression test was used to examine the effect of three factors: sample size, year of study, and age of the participants. According to Fig. 6, the prevalence of osteoporosis decreases with increasing the sample size, and this is statistically significant $(P<0.05)$. Moreover, Fig. 7 shows that the prevalence of osteoporosis decreases with increasing years of study, which is statistically significant $(P<0.05)$. The results reported in Fig. 8 show that the prevalence of osteoporosis studies in the world increases with age, which was also statistically significant $(P<0.05)$.

\section{Discussion}

In this study, the prevalence of osteoporosis in the world was $18.3 \%$, which is calculated based on reports of the prevalence of osteoporosis from 86 studies across five continents. Although the number of reported epidemiological studies on osteoporosis in Africa is limited, recent studies have shown that osteoporosis and related fractures increase across the continent [93]. Therefore, based on the results of this study, it was revealed that the prevalence of osteoporosis in Africa is much worse than that in other continents.

According to a systematic and meta-analysis study in China, the prevalence of osteoporosis from 2003 to October 2015 was reported to be $15.33 \%$ in men and $25.41 \%$ in women. It can be concluded that the overall prevalence of osteoporosis was 20\% [94].

In a study, the prevalence of osteoporosis was assessed in several industrialized countries (USA, Canada, five European countries, Australia, and Japan) and people aged 50 and over. The prevalence of osteoporosis in the spine or hip was reported as follows: $26.3 \%$ in Japan, $21 \%$ in the USA, 14.3\% in Germany, 9.9\% in France, 9.7\% in Italy, $7.8 \%$ in the United Kingdom, 6.3\% in Spain, 2.6\% in Canada, and $2 \%$ in Australia. Overall, the number of people with osteoporosis is estimated at 49 million [95].

In 2018, a systematic review and meta-analysis based on the World Health Organization (WHO) diagnostic 


\section{Meta Analysis}

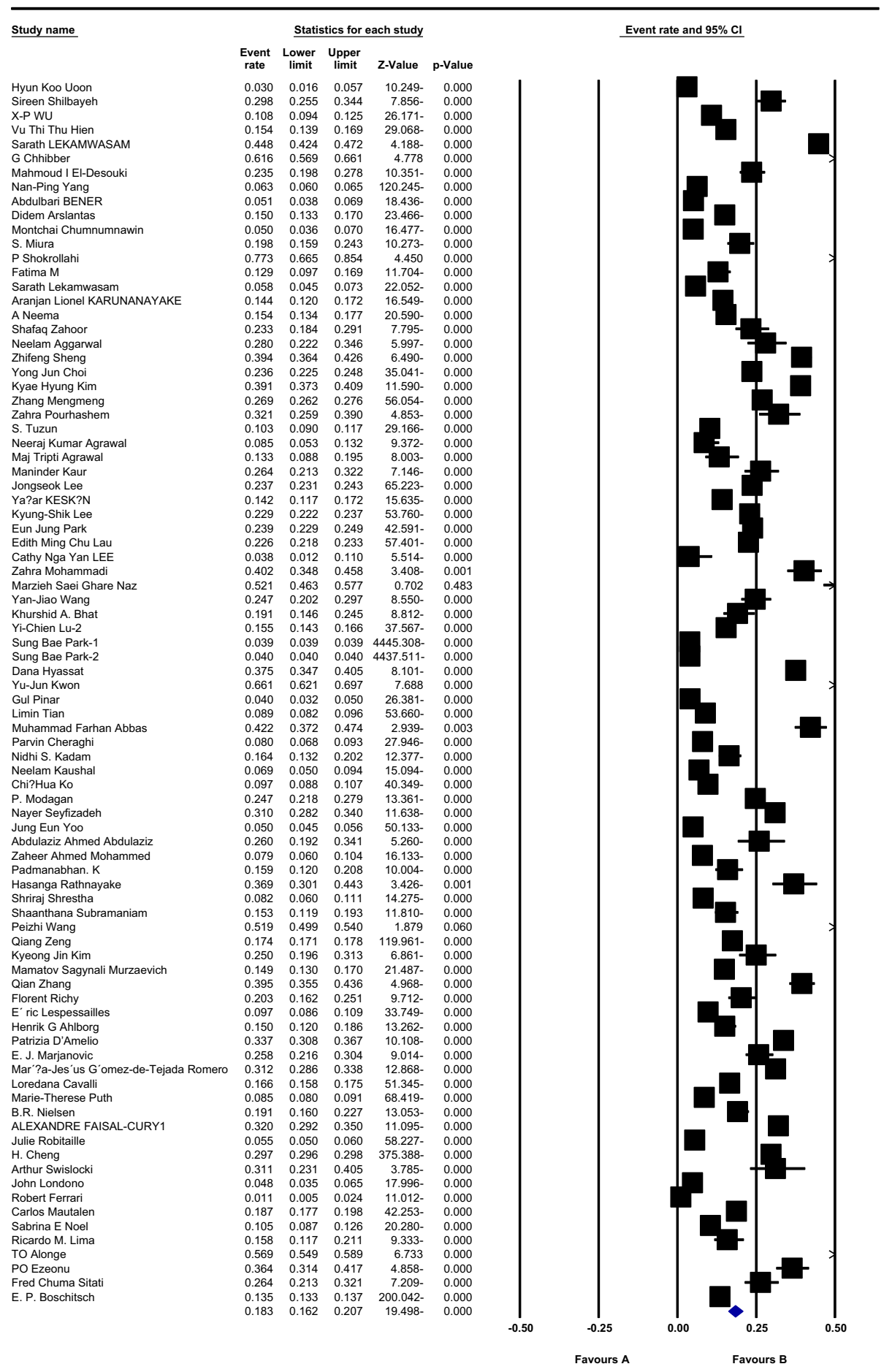

\section{Meta Analysis}

Fig. 3 Overall prevalence of osteoporosis in the world based on a random effects model 
Table 2 Results of meta-analysis by continents and diagnosis tools

\begin{tabular}{|c|c|c|c|c|c|}
\hline Subgroup & Number of articles & Sample size & $I^{2}$ & $\begin{array}{l}\text { Publication bias (Begg and } \\
\text { Mazumdar test) }\end{array}$ & Prevalence $\%(95 \% \mathrm{Cl})$ \\
\hline \multicolumn{6}{|l|}{ Continents } \\
\hline Asia & 64 & $102,279,215$ & 99.9 & 0.106 & 16.7 (95\% Cl 15.9-17.5) \\
\hline Europe & 9 & 24,481 & 99.1 & 1.000 & 18.6 (95\% Cl 12.9-26) \\
\hline America & 9 & 928,492 & 99.6 & 0.916 & 12.4 (95\% Cl 7.4-19.5) \\
\hline Africa & 3 & 2989 & 98.2 & 0.296 & 39.5 (95\% Cl 22.3-59.7) \\
\hline Australia & 1 & 99,399 & 100 & - & $13.5(95 \%$ Cl 13.3-13.7) \\
\hline \multicolumn{6}{|l|}{ Diagnosis tools } \\
\hline $\mathrm{BMD}(\mathrm{DXA})$ & 71 & $102,398,640$ & 99.9 & 0.112 & $19(95 \% \mathrm{Cl} 18-20)$ \\
\hline BMD by (DEXA) & 11 & 923,401 & 99.3 & 0.533 & 19.6 (95\% Cl 14.3-26.2) \\
\hline SOS & 3 & 4116 & 92.2 & 1.000 & 14.8 (95\% Cl 10.9-19.7) \\
\hline
\end{tabular}

criteria were conducted in the eastern Mediterranean: the study was conducted between 2000 and 2017 without any language restrictions; the prevalence of osteoporosis was $24.4 \%$; the prevalence of osteoporosis is $24.4 \%$ in women and $20.5 \%$ in men [96].

The present study examined the PubMed, Science Direct, Web of Science, Scopus, Magiran, and Google Scholar databases that were searched with no lower time limit and until 2020. According to PRISMA checklist and flow chart, while Zamani et al. [96] studied only PubMed, Scopus, Web of Science, and Index Medicus for the EMR published between January 2000 and December 2017, we can say that the sensitivity of this study by examining more databases and finding more relevant studies is more than the study of Zamani et al. [96]. In addition, this study has been studied worldwide and by gender in all continents, but the study of Zamani et al. [96] has examined only the Eastern Mediterranean.

The prevalence of osteoporosis in women of the world was reported to be 23.1 (95\% CI 19.8-26.9), and the prevalence of osteoporosis in men of the world was reported to be 11.7 (95\% CI 9.6-14.1). The results of subgroup analysis also show that among men, the highest prevalence of osteoporosis was in Asia and among women, the highest prevalence of osteoporosis was in Africa, this is even though no studies have been conducted on men in the African continent and no African studies of men in the meta-analysis.

The highest prevalence of osteoporosis in the studies studied in Iran with $77.3 \%$ and the lowest prevalence in the Canadian study with $1.07 \%$ [30, 85]. Osteoporosis affects both males and females. Although the definition of osteoporosis is not necessarily associated with fractures, the unfortunate consequence is fractures [96-100]. The analysis showed that out of the diagnostic tools used to diagnose osteoporosis, the prevalence of osteoporosis was highest when diagnosed with BMD instruments.

According to a study in 1995 in the USA, approximately 1.5 million fractures are associated with osteoporosis each year. It is estimated that $80 \%$ of India's urban

Table 3 Results of meta-analysis by continents stratified by sex

\begin{tabular}{|c|c|c|c|c|c|}
\hline Continents (sex) & Number of articles & Sample size & $P^{2}$ & $\begin{array}{l}\text { Begg and Mazumdar } \\
\text { test }\end{array}$ & Prevalence $\%(95 \% \mathrm{Cl})$ \\
\hline \multicolumn{6}{|l|}{ Asia } \\
\hline Men & 31 & 85,636 & 99.3 & 0.414 & 11.7 (95\% Cl 8.8-15.5) \\
\hline Women & 51 & 113,431 & 99.3 & 0.188 & 24.3 (95\% Cl 21.2-27.8) \\
\hline \multicolumn{6}{|l|}{ Europe } \\
\hline Men & 4 & 6695 & 98.1 & 0.308 & 9.7 (95\% Cl 4.4-18.5) \\
\hline Women & 8 & 17,786 & 98.7 & 0.710 & $19.8(95 \%$ Cl 14.5-26.5) \\
\hline \multicolumn{6}{|l|}{ America } \\
\hline Men & 4 & 360,669 & 96.09 & 0.734 & $8.5(95 \%$ Cl 3.7-14.1) \\
\hline Women & 7 & 567,823 & 99.8 & 1.000 & 15.1 (95\% Cl 6.9-29.9) \\
\hline \multicolumn{6}{|l|}{ Africa } \\
\hline Men & - & - & - & - & - \\
\hline Women & 3 & 2018 & 98.9 & 0.296 & 42.4 (95\% Cl 19.9-56.5) \\
\hline
\end{tabular}




\section{Meta Analysis}

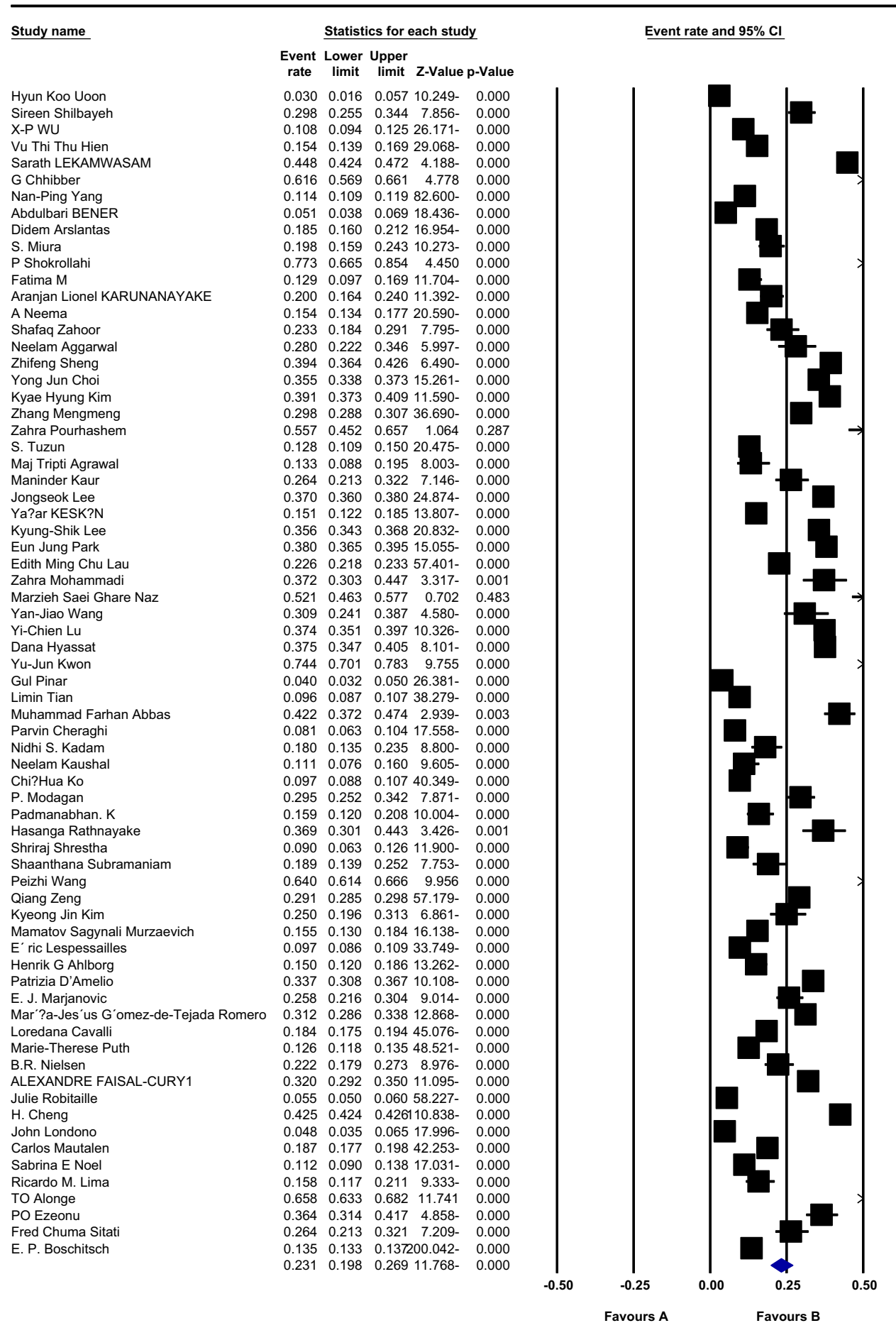

\section{Meta Analysis}

Fig. 4 Overall prevalence of osteoporosis in women of the world based on a random effects model 


\section{Meta Analysis}

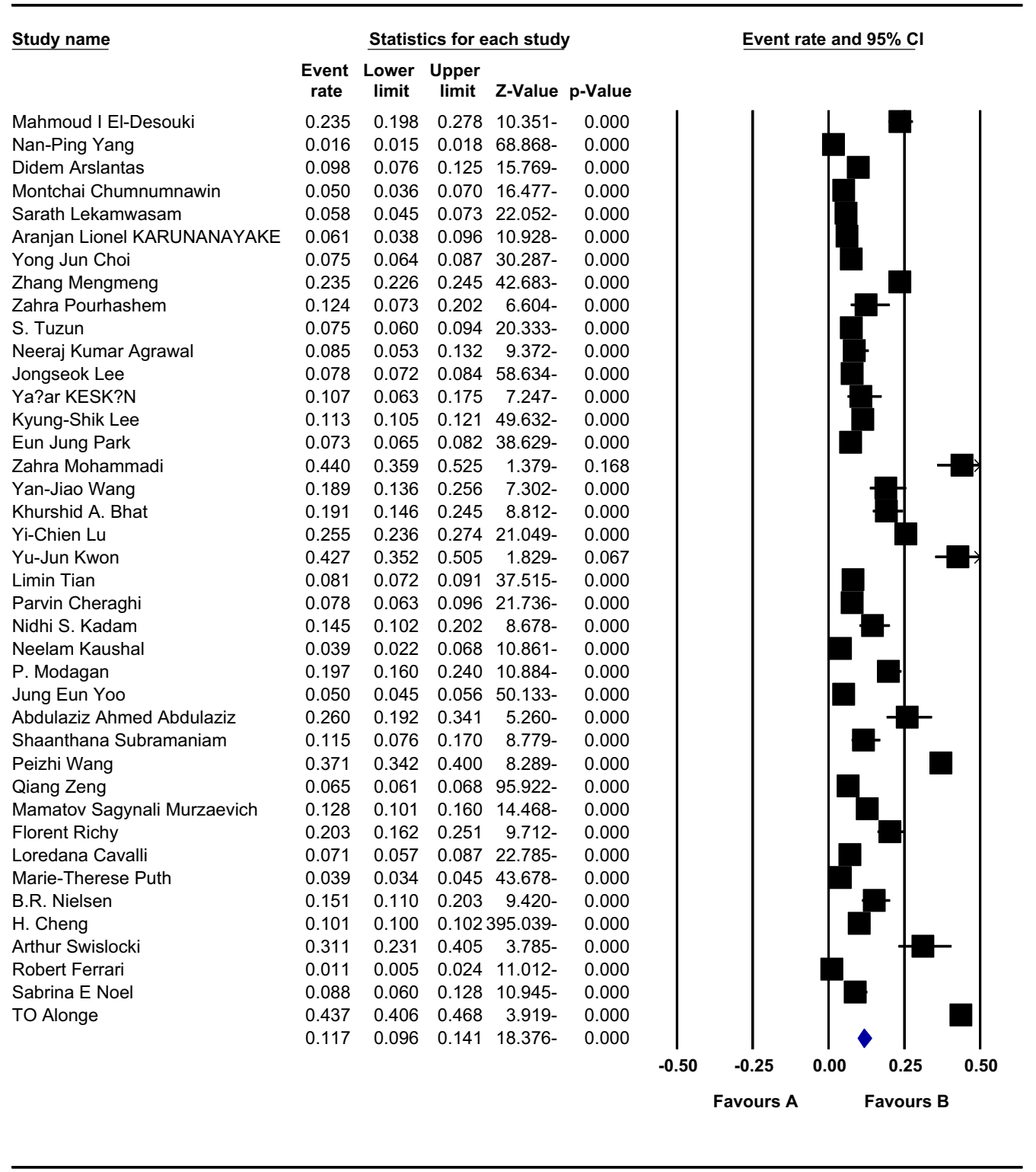

Meta Analysis

Fig. 5 Overall prevalence of osteoporosis in men of the world based on a random effects model

population suffers from a deficiency of Vitamin D and hip fractures occur about a decade earlier than in Western nations. Therefore, osteoporosis is a major concern for this ageing population $[101,102]$.

Although there is no direct evidence that screening for osteoporosis reduces fractures, there is good indirect evidence that screening is effective in identifying post-menopausal women with low bone mineral density. Health policymakers can also help prevent and reduce osteoporosis in the community through a variety of means, such as moderate physical activity, an appropriate intake of calcium and vitamin $\mathrm{D}$, cessation of smoking, and pharmaceutical intervention in high-risk groups. Also, effective dissemination of findings from research should be used to increase the awareness of osteoporosis, both among the general population and in the health services, to increase early detection of risk factors and to motivate preventive measures [90-102]. 


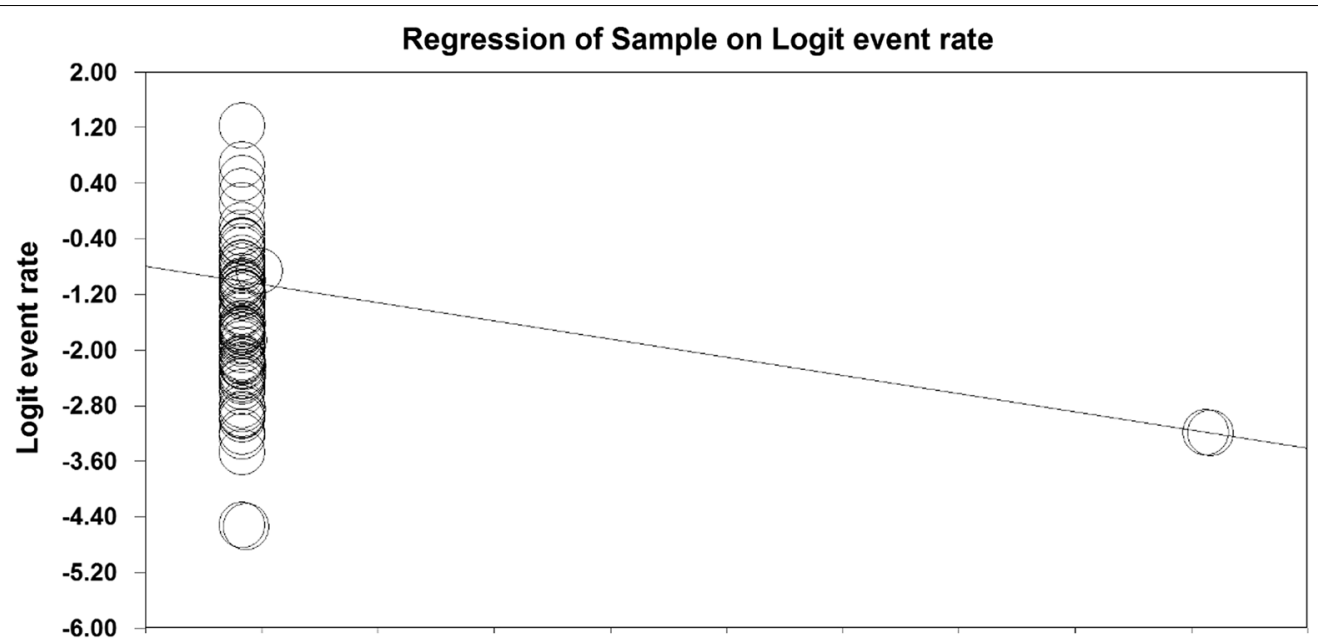

$-5116831002345671637441330403219444320195846082072489632865184400054725014576066286048$ Sample

Fig. 6 Meta-regression diagram of the prevalence of osteoporosis in the world by sample size

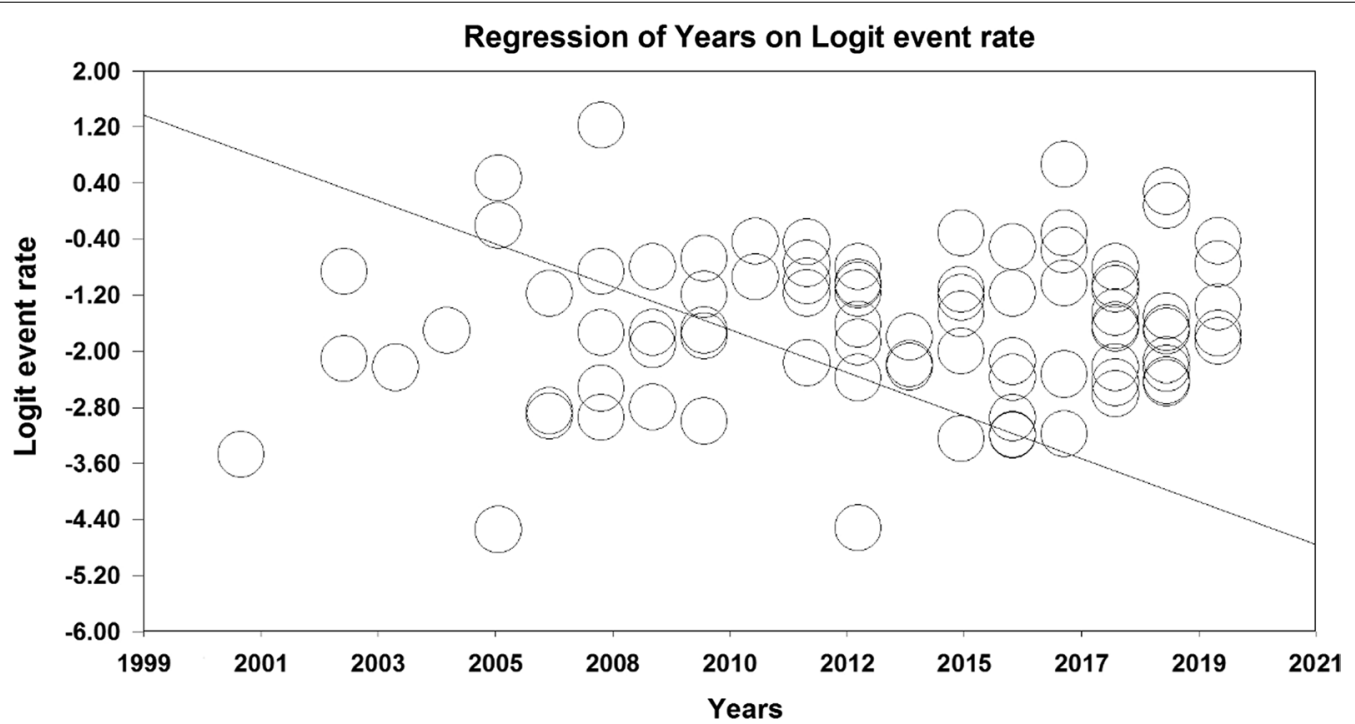

Fig. 7 Meta-regression diagram of the prevalence of osteoporosis in the world by year of study

\section{Strengths and limitation}

The most important strength of the present study is the comprehensive review of all databases, regular review of articles by three researchers and performing metaregression and subgroup analysis to obtain more accurate information. The most important limitations of the present study were to encounter low-quality articles that had been published for years and their full text was not available for further review.

The present study aims to remove the limitations of systematic review studies and other meta-analyses in this field by using a comprehensive review of different sources, long time period, different meta-regression and subgroup analysis, and considering that articles in languages other than English and Persian were not considered and age-specific prevalence of osteoporosis were not reported, can be mentioned as limitations of this study.

\section{Conclusion}

This study shows that the prevalence of osteoporosis in the world is very high, especially the prevalence in Africa and Europe is much higher and more significant. According to the medical, economic, and social burden of osteoporosis, providing a robust and comprehensive estimate 


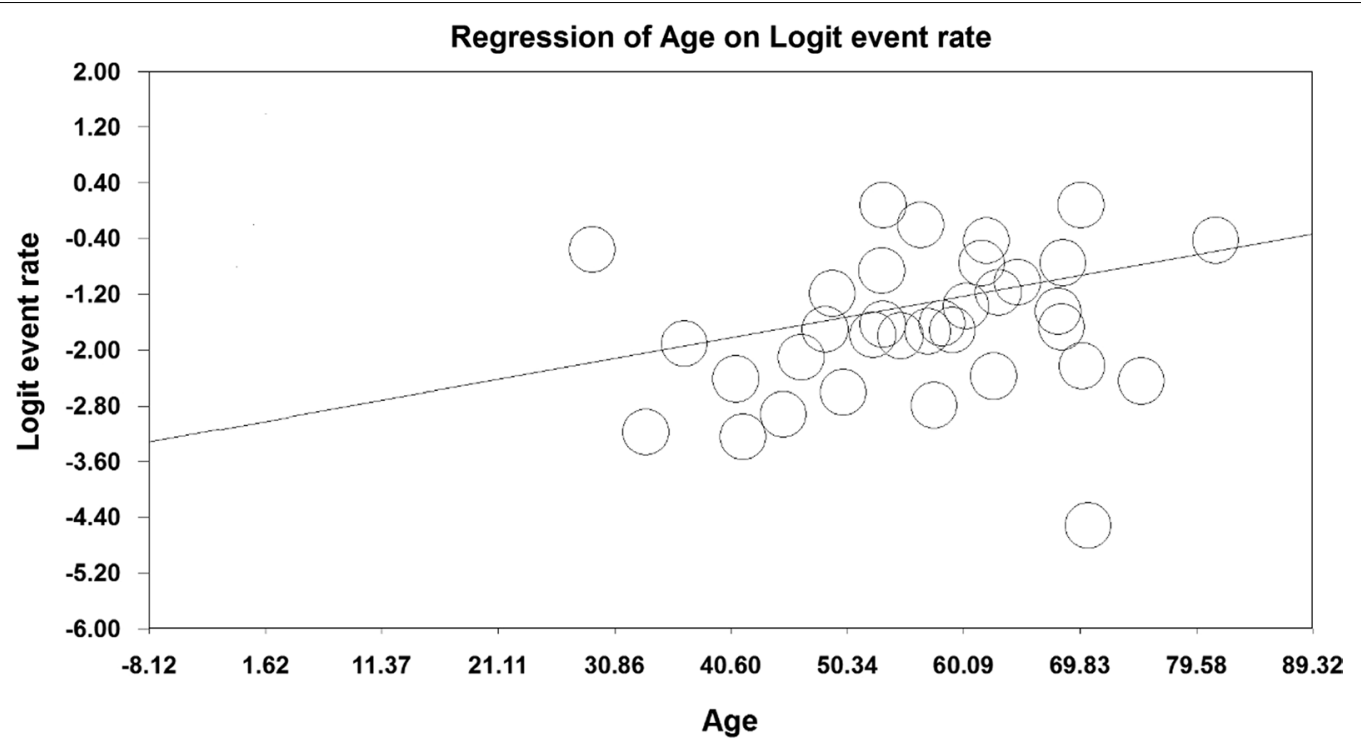

Fig. 8 Meta-regression diagram of the prevalence of osteoporosis in the world by age of study participants

of the prevalence of osteoporosis in the world can facilitate decisions in health system planning and policymaking, including an overview of the current and outlook for the future; provide the necessary facilities for the treatment of people with osteoporosis; reduce the severe risks that lead to death by preventing fractures.

\section{Abbreviations}

BMD: Bone mineral density; DXA: Dual-energy X-ray absorptiometry; SOS: Speed of sound; STROBE: Strengthening the Reporting of Observational Studies in Epidemiology for Cross-Sectional Study; PRISMA: Preferred Reporting Items for Systematic Reviews and Meta-Analysis.

\section{Acknowledgements}

The authors thank the Student Research Committee of Kermanshah University of Medical Sciences.

\section{Authors' contributions}

MM and NS and LM and HGH contributed to the design, MM statistical analysis, participated in most of the study steps. MHB and MM and NS and ER prepared the manuscript. SHSH and LM and MM assisted in designing the study and helped in the interpretation of the study. All authors read and approved the final manuscript.

\section{Funding}

By Deputy for Research and Technology, Kermanshah University of Medical Sciences (IR) (3010862). This deputy has no role in the study process.

\section{Availability of data and materials}

Datasets are available through the corresponding author upon reasonable request.

\section{Declarations}

\section{Ethics approval and consent to participate}

Ethics approval was received from the ethics committee of the deputy of research and technology, Kermanshah University of Medical Sciences (IR. KUMS.REC.1399.929).
Consent for publication

Not applicable.

\section{Competing interests}

The authors declare that they have no conflict of interest.

\section{Author details}

${ }^{1}$ Department of Biostatistics, School of Health, Kermanshah University of Medical Sciences, Kermanshah, Iran. ${ }^{2}$ Student Research Committee, Kermanshah University of Medical Sciences, Kermanshah, Iran. ${ }^{3}$ Department of Statistics, Science and Research Branch, Islamic Azad University, Tehran, Iran ${ }^{4}$ Department of Biology, Faculty of Science, University Putra Malaysia, Serdang, Selangor, Malaysia. ${ }^{5}$ Department of Nursing, School of Nursing and Midwifery, Kermanshah University of Medical Sciences, Kermanshah, Iran.

Received: 26 August 2021 Accepted: 4 October 2021

Published online: 17 October 2021

\section{References}

1. Mohammed ZA, Almeshal MA, Aldawsari SA, Alanazi MA, Alanazi $A D$, Alqahtani FA, et al. Prevalence of fracture and osteoporosis and awareness of osteoporosis among general population of Majmaah City IN 2018. Indo Am J Pharmaceut Sci. 2019;6(1):357-61.

2. Marcucci G, Brandi ML. Rare causes of osteoporosis. Clin Cases Miner Bone Metab. 2015;12(2):151.

3. Aoki TT, Grecu EO, Srinivas PR, Prescott P, Benbarka M, Arcangeli MM. Prevalence of osteoporosis in women: variation with skeletal site of measurement of bone mineral density. Endocr Pract Off J Am Coll Endocrinol Am Assoc Clin Endocrinol. 2000;6(2):127-31.

4. Wu XP, Liao EY, Luo XH, Dai RC, Zhang H, Peng J. Age-related variation in quantitative ultrasound at the tibia and prevalence of osteoporosis in native Chinese women. Br J Radiol. 2003:76(909):605-10.

5. Askari M, Lotfi MH, Owlia MB, Fallahzadeh H, Mohammadi M. Survey of osteoporosis risk factors (review article). J Sabzevar Univ Med Sci. 2019;25(6):854-63.

6. Faisal-Cury A, Zacchello KP. Osteoporosis: prevalence and risk factors among $>49$ year-old women in private practice environment. Acta Ortop Bras. 2007;15(3):146-50.

7. Pinar G, Kaplan S, Pinar T, Akalin A, Abay H, Akyol M, et al. The prevalence and risk factors for osteoporosis among 18- to 49-year-old Turkish women. Women Health. 2017:57(9):1080-97. 
8. Zhang Q, Cai WW, Wang GH, Shen XJ. Prevalence and contributing factors of osteoporosis in the elderly over 70 years old: an epidemiological study of several community health centers in Shanghai. Ann Palliat Med. 2020;9(2):231-8.

9. Jalava T, Sarna S, Pylkkänen L, Mawer B, Kanis JA, Selby P, et al. Association between vertebral fracture and increased mortality in osteoporotic patients. J Bone Miner Res. 2003;18(7):1254-60.

10. Aicale R, Tarantino D, Maccauro G, Peretti GM, Maffulli N. Genetics in orthopaedic practice. J Biol Regul Homeost Agents. 2019;33(2 Suppl. 1):103-17.

11. Conti V, Russomanno G, Corbi G, Toro G, Simeon V, Filippelli W, et al. A polymorphism at the translation start site of the vitamin $D$ receptor gene is associated with the response to anti-osteoporotic therapy in postmenopausal women from southern Italy. Int J Mol Sci. 2015;16(3):5452-66.

12. Jarupanich T. Prevalence and risk factors associated with osteoporosis in women attending menopause clinic at Hat Yai Regional Hospital. J Med Assoc Thailand Chotmaihet Thangphaet. 2007;90(5):865-9.

13. Lee CNY, Lam SC, Tsang AYK, Ng BTY, Leung JCY, Chong ACY. Preliminary investigation on prevalence of osteoporosis and osteopenia: should we tune our focus on healthy adults? Jpn J Nurs Sci. 2015;12(3):232-48.

14. Cheng H, Gary LC, Curtis JR, Saag KG, Kilgore ML, Morrisey MA, et al. Estimated prevalence and patterns of presumed osteoporosis among older Americans based on Medicare data. Osteoporos Int J Establ Result Coop Between Eur Found Osteoporos Natl Osteoporos Found U S A. 2009;20(9):1507-15.

15. Park SB, Kim J, Jeong JH, Lee JK, Chin DK, Chung CK, et al. Prevalence and incidence of osteoporosis and osteoporotic vertebral fracture in Korea: nationwide epidemiological study focusing on differences in socioeconomic status. Spine. 2016:41(4):328-36.

16. Vu TT, Nguyen CK, Nguyen TL, Le BM, Le NguyenTrung D, Bui TN, et al. Determining the prevalence of osteoporosis and related factors using quantitative ultrasound in Vietnamese adult women. Am J Epidemiol. 2005;161(9):824-30.

17. Modagan P, Silambanan S, Menon PG, Arunalatha P. Comparison of bone mineral density with biochemical parameters and prevalence of osteopenia and osteoporosis in South Indian population. Biomed Pharmacol J. 2018;11(4):2209-14.

18. Kaushal N, Vohora D, Jalali RK, Jha S. Prevalence of osteoporosis and osteopenia in an apparently healthy Indian population-a cross-sectional retrospective study. Osteoporos Sarcopenia. 2018;4(2):53-60.

19. Yang N-P, Deng C-Y, Chou Y-J, Chen P-Q, Lin C-H, Chou P, et al. Estimated prevalence of osteoporosis from a Nationwide Health Insurance database in Taiwan. Health Policy (Amsterdam, Netherlands). 2006;75(3):329-37.

20. Kazeminia M, Abdi A, Shohaimi SH, Jalali R, Vaisi-Raygani AK, Salari N. Dental caries in primary and permanent teeth in children's worldwide, 1995 to 2019: a systematic review and meta-analysis. Head Face Med. 2020;16(1):22

21. El-Desouki MI, Sulimani RA. High prevalence of osteoporosis in Saudi men. Saudi Med J. 2007;28(5):774-7.

22. Yoon HK, Kim SW, Yim CH, Chung HY, Oh HJ, Han KO, et al. Metabolic characteristics and prevalence of osteoporosis among women in TaeAn area. J Korean Med Sci. 2001;16(3):323-7.

23. Shilbayeh S. Prevalence of osteoporosis and its reproductive risk factors among Jordanian women: a cross-sectional study. Osteoporos Int J Establ Result Coop Between Eur Found Osteoporos Natl Osteoporos Found U S A. 2003;14(11):929-40.

24. Lekamwasam S, Wijerathne L, Rodrigo M, Hewage U. Prevalence of osteoporosis among post-menopausal women in Sri Lanka. Osteoporos Int. 2006;17(6):955.

25. Roy R, Chibber G, Marumudi E, Srivasta M, Ammini AC. Prevalence of osteoporosis among elderly women living in Delhi and rural Haryana. Osteoporos Int. 2006;17:5208.

26. Bener A, Hammoudeh M, Zirie M. Prevalence and predictors of osteoporosis and the impact of life style factors on bone mineral density. APLAR J Rheumatol. 2007;10(3):227-33.

27. Arslantas D, Metintasa S, Unsal A, Isikli B, Kalyoncu C, Arslantas A. Prevalence of osteoporosis in middle anatolian population using calcaneal ultrasonography method. Maturitas. 2008;59(3):234-41.
28. Chumnumnawin M, Sawetchaikul S, Sresuriyasawad V. Prevalence of osteoporosis of the priests. J Med Assoc Thailand Chotmaihet Thangphaet. 2008;91(Suppl 1):S57-62.

29. Miura S, Saavedra OL, Yamamoto S. Osteoporosis in urban post-menopausal women of the Philippines: prevalence and risk factors. Arch Osteoporos. 2008;3(1-2):17-24.

30. Shokrollahi P, Rivaz M, Robatjaze M. Prevalence of risk factors of osteoporosis in post-menopausal women in Shiraz, Southern Iran. Iran Red Crescent Med J. 2008;10(3):190-3.

31. Fatima M, Nawaz H, Kassi M, Rehman R, Kasi PM, Kassi M, et al. Determining the risk factors and prevalence of osteoporosis using quantitative ultrasonography in Pakistani adult women. Singap Med J. 2009;50(1):20-8.

32. Lekamwasam S, Wijayaratne L, Rodrigo M, Hewage U. Prevalence and determinants of osteoporosis among men aged 50 years or more in Sri Lanka: a community-based cross-sectional study. Arch Osteoporos. 2009;4(1-2):79-84.

33. Karunanayake AL, Pinidiyapathirage MJ, Wickremasinghe AR. Prevalence and predictors of osteoporosis in an urban Sri Lankan population. Int J Rheum Dis. 2010;13(4):385-90.

34. Neema A, Shweta V, Inamdar SA. Prevalence of osteoporosis using quantitative ultrasound for menopausal women in rural and urban area. Internet J Gynecol Obstet. 2010;13:1.

35. Zahoor S, Ayub U. Prevalence of osteoporosis in post-menopausal women visiting police and services hospital Peshawar, NWFP. J Postgrad Med Inst. 2010;24(1):04-7.

36. Aggarwal N, Raveendran A, Khandelwal N, Sen RK, Thakur JS, Dhaliwal $L K$, et al. Prevalence and related risk factors of osteoporosis in peri- and post-menopausal Indian women. J Mid Life Health. 2011;2(2):81-5.

37. Sheng Z, Xu K, Ou Y, Dai R, Luo X, Liu S, et al. Relationship of body composition with prevalence of osteoporosis in central south Chinese post-menopausal women. Clin Endocrinol. 2011;74(3):319-24.

38. Choi YJ, Oh HJ, Kim DJ, Lee Y, Chung YS. The prevalence of osteoporosis in Korean adults aged 50 years or older and the higher diagnosis rates in women who were beneficiaries of a national screening program: the Korea National Health and Nutrition Examination Survey 2008-2009. J Bone Miner Res Off J Am Soc Bone Miner Res. 2012;27(9):1879-86.

39. Kim KH, Lee K, Ko Y-J, Kim SJ, Oh SI, Durrance DY, et al. Prevalence, awareness, and treatment of osteoporosis among Korean women: the Fourth Korea National Health and Nutrition Examination Survey. Bone. 2012;50(5):1039-47.

40. Mengmeng Z, Yagang L, Ying L, Xuena P, Binbin L, Liu Z. A study of bone mineral density and prevalence of osteoporosis in Chinese people of Han nationality from Changchun. Arch Osteoporos. 2012;7:31-6.

41. Pourhashem Z, Bayani M, Noreddini H, Bijani A, Hosseini SR. Prevalence of osteoporosis and its association with serum vitamin $D$ level in older people in Amirkola, North of Iran. Caspian J Intern Med. 2012;3(1):347-53.

42. Tuzun S, Eskiyurt N, Akarirmak U, Saridogan M, Senocak M, Johansson H, et al. Incidence of hip fracture and prevalence of osteoporosis in Turkey: the FRACTURK study. Osteoporos Int. 2012;23(3):949-55.

43. Agrawal NK, Sharma B. Prevalence of osteoporosis in otherwise healthy Indian males aged 50 years and above. Arch Osteoporos. 2013;8:116.

44. Agrawal T, Verma AK. Cross sectional study of osteoporosis among women. Med J Armed Forces India. 2013;69(2):168-71.

45. Kaur M. Prevalence and associated risk factors of osteoporosis in postmenopausal women in North India. Malays J Nutr. 2013;19(3):285-92.

46. Lee J, Lee S, Jang S, Ryu OH. Age-related changes in the prevalence of osteoporosis according to gender and skeletal site: the Korea National Health and Nutrition Examination Survey 2008-2010. Endocrinol Metab (Seoul, Korea). 2013;28(3):180-91.

47. Keskin Y, Cekin MD, Gunduz H, Luleci NE, Giray E, Sur H, et al. The prevalence of osteoporosis in the Thrace Region of Turkey: a communitybased study. Turkiye Fiziksel Tip Ve Rehabilitasyon Dergisi Turk J Phys Med Rehabil. 2014;60(4):335-40.

48. Lee KS, Bae SH, Lee SH, Lee J, Lee DR. New reference data on bone mineral density and the prevalence of osteoporosis in Korean adults aged 50 years or older: the Korea National Health and Nutrition Examination Survey 2008-2010. J Korean Med Sci. 2014;29(11):1514-22.

49. Park EJ, Joo IW, Jang MJ, Kim YT, Oh K, Oh HJ. Prevalence of osteoporosis in the Korean population based on Korea National Health and 
Nutrition Examination Survey (KNHANES), 2008-2011. Yonsei Med J. 2014;55(4):1049-57.

50. Lau EMC, Chung HL, Ha PC, Tang H, Lam D. Bone mineral density, anthropometric indices, and the prevalence of osteoporosis in Northern (Beijing) Chinese and Southern (Hong Kong) Chinese Women-the largest comparative study to date. J Clin Densitom. 2015;18(4):519-24.

51. Mohammadi Z, Keshtkar A, Fayyazbakhsh F, Ebrahimi M, Amoli MM, Ghorbani M, et al. Prevalence of osteoporosis and vitamin D receptor gene polymorphisms (Fokl) in an Iranian general population based study (Kurdistan) (IMOS). Med J Islam Repub Iran. 2015;29:238.

52. Saei Ghare Naz M, Ozgoli G, Aghdashi MA, Salmani F. Prevalence and risk factors of osteoporosis in women referring to the bone densitometry academic center in Urmia, Iran. Glob J Health Sci. 2015;8(7):135-45.

53. Wang YJ, Wang Y, Zhan JK, Tang ZY, He JY, Tan P, et al. Sarco-osteoporosis: prevalence and association with frailty in Chinese communitydwelling older adults. J Am Geriatr Soc. 2015;63:S352-3.

54. Bhat KA, Kakaji M, Awasthi A, Shukla M, Dubey M, Srivastava R, et al. High prevalence of osteoporosis and morphometric vertebral fractures in Indian males aged 60 years and above: should age for screening be lowered? J Clin Densitom Off J Int Soc Clin Densitom. 2018;21(4):517-23.

55. Lu YC, Lin YC, Lin YK, Liu YJ, Chang KH, Chieng PU, et al. Prevalence of osteoporosis and low bone mass in older Chinese population based on bone mineral density at multiple skeletal sites. Sci Rep. 2016;6:25206.

56. Hyassat D, Alyan T, Jaddou H, Ajlouni KM. Prevalence and risk factors of osteoporosis among Jordanian postmenopausal women attending the National Center for Diabetes, Endocrinology and Genetics in Jordan. BioResearch Open Access. 2017;6(1):85-93.

57. Kwon YJ, Park KS, Choi BH, Kim BS, Ha YC. Prevalence of osteoporosis and effectiveness of screening test using ultrasound bone densitometry and education in a community-dwelling population. J Korean Med Sci. 2017;32(2):352-6.

58. Tian L, Yang R, Wei L, Liu J, Yang Y, Shao F, et al. Prevalence of osteoporosis and related lifestyle and metabolic factors of post-menopausal women and elderly men: a cross-sectional study in Gansu province, Northwestern of China. Medicine. 2017;96(43):e8294.

59. Abbas MF, Abbas F, Asghar MS. Prevalence of osteoporosis and associated risk factors in women. Indo Am J Pharmaceut Sci. 2018;5(12):15659-63.

60. Cheraghi $\mathrm{P}, \mathrm{Cheraghi} Z$, Bozorgmehr S. The prevalence and risk factors of osteoporosis among the elderly in Hamadan province: a cross sectional study. Med J Islam Repub Iran. 2018;32:111.

61. Kadam NS, Chiplonkar SA, Khadilkar AV, Khadilkar WV. Prevalence of osteoporosis in apparently healthy adults above 40 years of age in Pune City, India. Indian J Endocrinol Metab. 2018;22(1):67-73.

62. Seyfizadeh N, Seyfizadeh N, Negahdar H, Hosseini SR, Nooreddini H, Parsian H. ABO blood group and prevalence of osteoporosis and osteopenia in the elderly population: an Amirkola Health and Ageing Project (AHAP)-based study. J Clin Densitom Off J Int Soc Clin Densitom. 2018;21(2):200-4.

63. Yoo JE, Park HS. Prevalence and associated risk factors for osteoporosis in Korean men. Arch Osteoporos. 2018;13(1):88.

64. Abdulaziz AA, Hendi OM, Abdelbaky A, Alzaidi SA, Abdulaziz GA Abdulaziz RA. Prevalence and risk factors of osteoporosis in women aged above 60 years at Taif Governorate, Saudi Arabia. Indo Am J Pharmaceut Sci. 2019;6(1):773-80.

65. Padmanabhan K, Paul J, Sudhakar S, Senthil Selvam P, Sathya Priya V, Veena KS. Which is more prevalent among the female populationosteopenia or osteoporosis? A cross sectional study. Res J Pharmacy Technol. 2019;12(3):1163-8.

66. Rathnayake H, Lekamwasam S, Wickramatilake C, Lenora J. Trabecular bone score and bone mineral density reference data for women aged 20-70 years and the effect of local reference data on the prevalence of post-menopausal osteoporosis: a cross-sectional study from Sri Lanka. Arch Osteoporos. 2019;14(1):91.

67. Shrestha S, Dahal S, Bhandari P, Bajracharya S, Marasini A. Prevalence of osteoporosis among adults in a tertiary care hospital: a descriptive cross-sectional study. JNMA J Nepal Med Assoc. 2019;57(220):393-497.

68. Subramaniam S, Chan CY, Soelaiman IN, Mohamed N, Muhammad $\mathrm{N}$, Ahmad F, et al. Prevalence and predictors of osteoporosis among the Chinese population in Klang Valley, Malaysia. Appl Sci Basel. 2019;9(9):1820.

69. Wang PZ, Abdin E, Shafie S, Chong SA, Vaingankar JA, Subramaniam M. Estimation of prevalence of osteoporosis using OSTA and its correlation with sociodemographic factors, disability and comorbidities. Int J Environ Res Public Health. 2019;16(13):2338.

70. Zeng Q, Li N, Wang QQ, Feng J, Sun DM, Zhang Q, et al. The prevalence of osteoporosis in China, a nationwide, multicenter DXA survey. J Bone Miner Res. 2019;34(10):1789-97.

71. Kim KJ, An JH, Kim KJ, Yu JH, Kim NH, Yoo HJ, et al. Prevalence of osteoporosis among North Korean women refugees living in South Korea: a comparative cross-sectional study. BMJ Open. 2020;10(6):e036230.

72. Murzaevich MS, Imanalieva F, Uulu CM, Tagaev T, Yethindra V, Arstanbekovna M. Prevalence of osteopenia and osteoporosis in the Kyrgyz Republic. Indian J Forensic Med Toxicol. 2020;14(3):1980-4.

73. Richy F, Gourlay ML, Garrett J, Hanson L, Reginsterm J-Y. Osteoporosis prevalence in men varies by the normative reference. J Clin Densitom. 2004;7(2):127-33.

74. Lespessailles E, Cotte FE, Roux C, Fardellone P, Mercier F, Gaudin AF. Prevalence and features of osteoporosis in the French general population: the Instant study. Jt Bone Spine. 2009;76(4):394-400.

75. Ahlborg HG, Rosengren BE, Järvinen TL, Rogmark C, Nilsson JK, Sernbo $\mathrm{I}$, et al. Prevalence of osteoporosis and incidence of hip fracture in women - secular trends over 30 years. BMC Musculoskelet Disord. 2010;11:1-7.

76. D'Amelio P, Spertino E, Martino F, Isaia GC. Prevalence of post-menopausal osteoporosis in Italy and validation of decision rules for referring women for bone densitometry. Calcif Tissue Int. 2013;92(5):437-43.

77. Marjanovic EJ, Southern HN, Coates P, Adams JE, Walsh T, Horner K, et al. Do patients with osteoporosis have an increased prevalence of periodontal disease? A cross-sectional study. Osteoporos Int J Establ Result Coop Between Eur Found Osteoporos Natl Osteoporos Found U S A. 2013;24(7):1973-9.

78. Gómez-de-Tejada Romero MJ, Navarro Rodríguez MD, Saavedra Santana P, Quesada Gómez JM, Jódar Gimeno E, Sosa HM. Prevalence of osteoporosis, vertebral fractures and hypovitaminosis $D$ in postmenopausal women living in a rural environment. Maturitas. 2014;77(3):282-6.

79. Cavalli L, Guazzini A, Cianferotti L, Parri S, Cavalli T, Metozzi A, et al. Prevalence of osteoporosis in the Italian population and main risk factors: results of BoneTour Campaign. BMC Musculoskelet Disord. 2016;17(1):396

80. Puth MT, Klaschik M, Schmid M, Weckbecker K, Münster E. Prevalence and comorbidity of osteoporosis- a cross-sectional analysis on 10,660 adults aged 50 years and older in Germany. BMC Musculoskelet Disord. 2018;19(1):144.

81. Nielsen BR, Andersen HE, Haddock B, Hovind P, Schwarz P, Suetta C. Prevalence of muscle dysfunction concomitant with osteoporosis in a home-dwelling Danish population aged 65-93 years-the Copenhagen Sarcopenia study. Exp Gerontol. 2020;138:110974.

82. Robitaille J, Yoon PW, Moore CA, Liu T, Irizarry-Delacruz M, Looker AC, et al. Prevalence, family history, and prevention of reported osteoporosis in U.S. women. Am J Prev Med. 2008;35(1):47-54.

83. Swislocki A, Green JA, Heinrich G, Barnett CA, Meadows ID, Harmon EB, et al. Prevalence of osteoporosis in men in a VA rehabilitation center. Am J Manag Care. 2010;16(6):427-33.

84. Londono J, Valencia P, Santos AM, Gutiérrez LF, Baquero R, Valle-Oñate R Risk factors and prevalence of osteoporosis in premenopausal women from poor economic backgrounds in Colombia. Int J Women's Health. 2013:5:425-30.

85. Ferrari R. Prevalence of osteoporosis in men aged $65-75$ in a primary care setting. A practice audit after application of the Canadian 2010 guidelines for osteoporosis screening. Clin Rheumatol. 2015:34(3):523-7.

86. Mautalen C, Schianchi A, Sigal D, Gianetti G, Vidan V, Bagur A, et al. Prevalence of osteoporosis in women in Buenos Aires based on bone mineral density at the lumbar spine and femur. J Clin Densitom Off J Int Soc Clin Densitom. 2016;19(4):471-6.

87. Noel SE, Mangano KM, Griffith JL, Wright NC, Dawson-Hughes B, Tucker $\mathrm{KL}$. Prevalence of osteoporosis and low bone mass among Puerto 
Rican older adults. J Bone Miner Res Off J Am Soc Bone Miner Res. 2018;33(3):396-403.

88. Lima RM, de Oliveira RJ, Raposo R, Neri SGR, Gadelha AB. Stages of sarcopenia, bone mineral density, and the prevalence of osteoporosis in older women. Arch Osteoporos. 2019;14(1):38.

89. Alonge TO, Adebusoye LA, Ogunbode AM, Olowookere OO, Ladipo MMA, Balogun WO, et al. Factors associated with osteoporosis among older patients at the Geriatric Centre in Nigeria: a cross-sectional study. S Afr Fam Pract. 2017;59(3):87-93.

90. Ezeonu PO, Agwu UM, Ajah LO, Dimejesi IBO, Ogbonnaya LU, Umeora OUJ, et al. The prevalence of osteoporosis among antenatal clinic attendees in a rural mission hospital in South-East Nigeria. Niger I Clin Pract. 2017;20(12):1522-6.

91. Sitati FC, Gichangi P, Obimbo MM. Prevalence of osteoporosis and its associated factors among post-menopausal women in Kiambu County, Kenya: a household survey. Arch Osteoporos. 2020;15(1):31.

92. Boschitsch EP, Durchschlag E, Dimai HP. Age-related prevalence of osteoporosis and fragility fractures: real-world data from an Austrian Menopause and Osteoporosis Clinic. Climact J Int Menopause Soc. 2017;20(2):157-63.

93. Paruk F, Tsabasvi M, Kalla AA. Osteoporosis in Africa—where are we now. Clin Rheumatol. 2020:40:3419-28.

94. Chen P, Li Z, Hu Y. Prevalence of osteoporosis in China: a meta-analysis and systematic review. BMC Public Health. 2016;16(1):1039.

95. Wade SW, Strader C, Fitzpatrick LA, Anthony MS, O'Malley CD. Estimating prevalence of osteoporosis: examples from industrialized countries. Arch Osteoporos. 2014;9(1):182.

96. Zamani M, Zamani V, Heidari B, Parsian H, Esmaeilnejad-Ganji SM. Prevalence of osteoporosis with the World Health Organization diagnostic criteria in the Eastern Mediterranean Region: a systematic review and meta-analysis. Arch Osteoporos. 2018;13(1):129.

97. Irani AD, Poorolajal J, Khalilian A, Esmailnasab N, Cheraghi Z. Prevalence of osteoporosis in Iran: a meta-analysis. J Res Med Sci. 2013;18(9):759.

98. Wright NC, Looker AC, Saag KG, Curtis JR, Delzell ES, Randall S, et al. The recent prevalence of osteoporosis and low bone mass in the United States based on bone mineral density at the femoral neck or lumbar spine. J Bone Miner Res Off J Am Soc Bone Miner Res. 2014:29(11):2520-6.

99. Mithal A, Kaur P. Osteoporosis in Asia: a call to action. Curr Osteoporos Rep. 2012;10(4):245-7.

100. Riggs BL, Melton $L$. The worldwide problem of osteoporosis: insights afforded by epidemiology. Bone. 1995;17(5, Supplement 1):S505-11.

101. Mithal A, Bansal B, Kyer CS, Ebeling P. The Asia-Pacific Regional AuditEpidemiology, Costs, and Burden of Osteoporosis in India 2013: a report of International Osteoporosis Foundation. Indian J Endocrinol Metab. 2014;18(4):449.

102. Hernlund E, Svedbom A, Ivergård M, Compston J, Cooper C, Stenmark $J$, et al. Osteoporosis in the European Union: medical management, epidemiology and economic burden. A report prepared in collaboration with the International Osteoporosis Foundation (IOF) and the European Federation of Pharmaceutical Industry Associations (EFPIA). Arch Osteoporos. 2013;8(1-2):136.

\section{Publisher's Note}

Springer Nature remains neutral with regard to jurisdictional claims in published maps and institutional affiliations.
Ready to submit your research? Choose BMC and benefit from:

- fast, convenient online submission

- thorough peer review by experienced researchers in your field

- rapid publication on acceptance

- support for research data, including large and complex data types

- gold Open Access which fosters wider collaboration and increased citations

- maximum visibility for your research: over 100M website views per year

At BMC, research is always in progress.

Learn more biomedcentral.com/submissions 